medical psychology and child and adolescent psychiatry are included during the medical curriculum in the 7 years of study by Belgian medical graduates. They are also trained in aspects of the patient-doctor relationship during small-group sessions.

Postgraduate training and specialisation last 5 years, during which trainees work under the supervision of a 'maitre de stage' in adult psychiatry, as well as child and adolescent psychiatry, and they also spend 1 year in neurology, paediatrics or internal medicine.

One year of training can be done in research. At the end of the specialisation, the candidate must publish one paper in an international journal or present at an international conference. Training includes mandatory academic courses and an examination during the third year. Since 2002, specific training in child and adolescent psychiatry has been available. Following specialisation, trainees will have a specific registration number from the Institut National d'Assurance Maladie-Invalidité (National Institute of Illness and Disability Insurance).

\section{Psychiatric associations}

Psychiatric associations in Belgium are divided between adult and child disciplines, and French-speaking and Flemishspeaking organisations. The primary association is the Société Royale de Médecine Mentale de Belgique (Royal Society of Mental Medicine of Belgium), which was founded in 1869. It is responsible for the primary Belgian psychiatric journal, the Acta Psychiatrica Belgica. The Vlaamse Vereniging Voor Psychiatrie (Flemish Association of Psychiatry) represents the Flemish-speaking community of adult psychiatrists. The Société Belge Francophone de Psychiatrie et des Disciplines Associées de I'Enfance et de l'Adolescence (French Belgian Society of Psychiatry and Associated Disciplines of Childhood and Adolescence) represents the French-speaking child and adolescent mental health professionals and the De Vlaamse Vereniging voor Kinder- en Jeugdpsychiatrie is the Flemish equivalent.

These professional societies are responsible for specialist professional standards, education and providing advice on policy. They are responsible for mental health promotion and the organisation of scientific events and congresses each year.

The Belgian College of Neuropsychopharmacology and Biological Psychiatry (BCNBP) was founded in 1974 and represents the scientific body of psychiatrists in Belgium.

\section{Conclusion}

As a high-income European country, Belgium has a modern psychiatric infrastructure comprising policy, legislation, community care, education, training and research. The integration of policy and services may be limited by its linguistic and cultural diversity, and future care programmes and pathways may benefit from a more unified strategy. Community care has historically been seen as a priority and the legislation in 2000 supports this continuing trend.

\section{Sources}

Andriessen, K., Clara, A. \& Beuckx, K. (2002) The suicide prevention policy of a mental health centre. International Journal of Mental Health Promotion, 4, 20-23.

Baro F., Prims A. \& de Schouwer, P. (1984) Belgium: psychiatric care in a pluralist system. In Mental Health Care in the European Community (ed. S. P. Mangen), pp. 42-54. Croom Helm.

Der Minister van Consumentenzaken, Volksgezondheid en Leefmilieu and Aelvoet, M. (2000) Legislation Concerning Mental Health. Federale databank van de beoefenaars van de gezondheidszorgberoepen, Public Federal Service of Health, Food Chain Safety and Environment, January, 2004

Fava, G. A \& Ottolini, F. (2004) International trends in psychiatric research. A citation analysis. Services research and outcomes. Current Opinion in Psychiatry, 17, 283-287.

Simoens-Desmet, A. (1998) Rapport National 1998 du Resume Psychiatrique Minimum. Ministere des Affaires Sociale, Se la Santè, Publique et de l'Environment.

Van Heeringen, K. (2003) Unit for Suicide Research, University of Gent, Belgium. British Journal of Psychiatry, 183, 260-261.

World Health Organization (2005) Belgium. In Mental Health Atlas 2005. See http://www.who.int/globalatlas/default.asp (last accessed August 2008).

\title{
Mental health in Yemen: obstacles and challenges
}

\section{Maan A. Bari Qasem Saleh PhD ${ }^{1}$ and Ahmed Mohamed Makki MD}

${ }^{1}$ Associate Professor, Faculty of Medicine, Aden University, Yemen, email maanymha@yahoo.com ${ }^{2}$ Reporter, Health Committee, Shura Council, Past Deputy Minister of Health

\begin{abstract}
The Republic of Yemen, on the south-western coast of the Arabian Peninsula, was formed in 1990 when North and South Yemen united. Yemen covers $527970 \mathrm{~km}^{2}$. The capital is Sana'a. The country is divided into 20 governorates and one municipality. It has an elected president, an elected House of Representatives, and an appointed Shura Council. The president is head of state, and the prime minister is head of government. Suffrage is universal for
\end{abstract}

people aged 18 and older. The population of Yemen according to the 2004 census is about 20 million, but recent years have seen the arrival of many refugees.

Mental health in Yemen has been fortunate to receive government support, albeit modest, and benefits from human resource development projects. These projects have enabled Yemeni students to study psychiatry, psychology, psychiatric nursing and social work abroad. Mental health in 
Yemen has developed within a context of social development against wars, internal struggles, poverty, high rates of reproduction and illiteracy. Mental health disorders are closely connected to myth, superstition, witchcraft and jinns. There continues to be stigma associated with mental health and, by extension, with psychology and psychiatry.

\section{Human resources}

A survey conducted by the Yemeni Mental Health Association (YMHA) in 2006 gave a figure of 3580 professionals with at least a BA in psychology. These include 139 people working in higher academic institutions. There are 198 psychiatric nurses and 45 psychiatrists and neurologists, giving one psychiatrist or neurologist per 500000 population. There are only three child psychiatrists in the country and they work between hospitals and universities.

\section{Educational and training institutions}

Two types of institution provide education and training.

First, within the undergraduate programme, four departments of psychiatry, housed in university faculties of medicine, serve the national educational and accreditation professional development needs. The training programme in general medicine lasts 6 years. Medical students spend one semester in psychiatry and two in the behavioural sciences or medical psychology. Activities in psychiatry departments are limited to teaching, lecturing and examination, and do not include research or service activities to the community. Reasons for this include scarce resources and consequent limitations and loss of motivation, social stigma associated with mental health issues, newness of the discipline, and a critical shortage of experienced specialists.

Second, since 2003 the Yemeni Council for Medical Specialisation under the Ministry of Health has run local academic qualification programmes in psychiatry and clinical psychology. The qualification for this specialisation is dependent on the Arab Board System (a 4-year course). Unfortunately, there is little interest in psychiatry and to date there have been only three graduates of the diploma programme.

In 2003, a national academic qualification programme was established that provides 1 year of post-baccalaureate training in clinical psychology. By 2007, 30 individuals from the Sana'a and Aden governorates had graduated.

\section{Mental health services}

\section{Psychiatric hospitals}

There are only four psychiatric hospitals treating mental illness in Yemen; the one in Aden, built in 1966, is the oldest on the Arabian peninsula. The total number of beds in the country is nearly 850 (YMHA, 2006) and these are available in only four governorates. These hospitals are for adults and have no special sections for children. Patients who have a mental illness wander the streets of cities and towns. Others, in their thousands, are detained in family homes in oppressive conditions, which is especially difficult for women, for whom the oppression is twofold.

\section{Psychiatric clinics in general hospitals}

In response to the World Health Organization's direction concerning the provision of mental health services in governorate hospitals, a number of mental health out-patient clinics have been developed at public hospitals, to which psychiatrists are appointed. However, these services are not provided by all public hospitals, and are subject to suspension or termination due to staff shortages and budget constraints.

\section{Psychiatric clinics in prisons}

Patients who are mentally ill and who have a criminal record can be detained in correctional facilities. The second National Conference for Mental Health held in Sana'a in 2004, organised with the International Committee of the Red Cross, recommended that patients with a mental illness be separated from prisoners and placed in mental health hospitals.

\section{Private nursing homes}

There are estimated to be only five private nursing clinics, in four governorates, with a capacity of approximately 100 beds (YMHA, 2006). Some have no beds and function as out-patient clinics.

\section{Private clinics}

There are about 45 private mental health clinics in Yemen run by psychiatrists (YMHA, 2006). Psychologists work in some of these clinics, supervised by psychiatrists. Drugs and electroconvulsive therapy (ECT) are typical treatments in these settings. Some work within a collective therapeutic team model. There are no designated clinics for children.

\section{Patient management and treatment}

Successfully treating mental illness often involves using drugs prescribed by psychiatrists and, in rural areas, by psychologists. Although effective, medication is of limited use, as drugs are unaffordable for most. The use of ECT remains widespread. Few evidence-based treatment programmes are considered appropriate for this culture. There are individual settings where institutional or individual initiatives have led to the establishment of models that demonstrate the potential and effectiveness of mental health services in the Yemeni context.

\section{Psychiatric hospital data in Yemen}

Statistical data obtained from Yemeni psychiatric hospitals gave a patient population of 29519 (YMHA, 2006). Paranoia with schizophrenia was the most common diagnosis, followed by emotional disturbances (depression and anxiety), while epilepsy, still classed as a mental illness, was in third place.

\section{Epidemiology of suicide}

Suicide is a problem of great sensitivity, and much stigma and shame are connected to the act. According to available official data, suicides in Yemen totalled 243 in 2006 (YMHA, 2006), with the use of a firearm being the most common means.

\section{National Mental Health Programme}

The National Mental Health Programme was established in the late 1980s with help from the World Health Organization and the Ministries of Health from North and South Yemeni 
governments of the time. The project concentrated on treatment in mental hospitals and care of patients with a mental illness by qualified psychiatrists. The National Mental Health Programme responded to recommendations put forward by the first National Workshop on Mental Health in Yemen, in October 2002, organised with the International Committee of the Red Cross. The Mental Health Programme was established by ministerial resolution and administered within the primary care division of the Ministry of Health.

The Programme is still being developed and requires support in both human and material resources as well as the development of a database of resources, statistics and epidemiological information.

\section{Non-governmental organisations}

In Yemen, non-governmental organisations (NGOs) focusing on mental health have increased in quantity and quality since the Associations Law of 2001 permitted the formation of professional organisations. By 2006, there were seven associations in the country, with a membership of 1280 (Saleh, 2008).

The Yemeni Psychiatric and Neurological Association (YPNA) was established in 1989, while the YMHA was established in 1998. In general, most associations are new and struggling but continue to advocate for and provide services. These associations play influential roles in campaigning against physical, mental and sexual violence towards women and children. They organise celebrations for International Mental Health Day, conferences, workshops, seminars, publishing endeavours, radio and television programmes, and contributions to journals and magazines in mental health. Finally, they advocate for the establishment of a formal code of ethics and a Mental Health Act, often at great personal and emotional expense, which is rarely acknowledged.

\section{Publications}

There are two bi-annual journals published by the Yemen Psychological Association (YPA) (20 volumes), another by the Doctor and Clinical Psychologists' Association (DCPA) (3 volumes) and two newsletters published periodically by both the YMHA (30 volumes) and the Aden Central Psychiatric Hospital (10 volumes) (YMHA, 2006). The main obstacles are a lack of financial resources and technical facilities for printing and dissemination.

\section{Research}

Research in mental health is not well developed, because of a lack of capacity and the absence of research institutions. Graduate (PhD and MA) students and teaching faculty conduct most mental health research in universities. The YPA and the YMHA take an active role in launching research initiatives and community surveys related to a variety of mental health issues, including violence against women and children, qat addiction, female genital mutilation and suicide. A lack of sustainable funding remains the biggest obstacle to research.

\section{Mental health and leadership}

In November 1989, the President of the YPNA, Dr A. Khleadi, also became President of the Arab Psychiatric Association. In 1997 and in 2001, two professors from the Department of Behavioural Sciences, Faculty of Medicine Aden University, became vice presidents of the World Federation of Mental Health for the Middle East Region (Dr Hassen Khan and Dr Maan Saleh). In 2002, Dr Ahmed Makki became a member of the Shura Consultative Council and reporter for its Health Committee. In 2003, Dr Dugysh, from the Aden governorate, became the first neuropsychiatrist to be elected as a Yemeni member of parliament.

\section{Future challenges and goals}

Until Yemen develops its own research base, addressing the population's mental health needs will require creativity and commitment. Developing short- and long-term programmes requires adapting research knowledge and both regional and international experiences appropriately to the Yemeni landscape while accelerating Yemeni progress in the field.

Goals for the future include:

o fostering qualitative and quantitative improvements in graduate and postgraduate higher education and training in mental health (doing so will enable Yemen to train specialists with culturally appropriate skills who can respond to the needs of society)

offering annual scholarships abroad, for at least 5 years, across the different fields of mental health, with sensitivity to issues of gender

o broadening the faculty role so that university professors can engage in research while being supported by a clear administrative and legislative mandate

$\checkmark$ increasing the number of educational campaigns to reduce the stigma of mental illness

O mandating a political and national strategy for mental health that includes the participation of the Ministry of Health, Yemeni universities (faculties of medicine) and related mental health NGOs

o improving and developing services in all the governorates

getting the Ministry of Health, specialised associations, and concerned scientific departments of Yemeni universities to prepare laws to protect those who are mentally ill and to promote and develop the field as a priority

o strengthening communications with regional and international institutions with respect to mental health and its financing

joining efforts to establish an accurate database that is methodical and up to date, and that uses contemporary techniques in data collection and manipulation.

\section{Sources}

Ministry of Planning (2000) Human Resource Development Report Ministry of Planning.

Ministry of Planning (2004) Annual Statistics Book. Ministry of Planning. Ministry of Health (2007) Report on The National Program of Mental Health The Present Situation of Mental Health (unpublished). Ministry of Health.

Saleh, M. A. (2008) Experience of Mental Health Association in Yemen. Journal of Social Science, Aden University, 22, 55-62.

YMHA (Yemeni Mental Health Association) (2006) [Survey] Al-Seha-AlAqilia, No. 29-30. 